\title{
Farklı IBA (İndol-3-Bütirik Asit) Dozları ve Köklendirme Ortamlarının Bazı Tıbbi Bitkilerin Köklenmesi Üzerine Etkileri
}

\author{
Mehmet Necat İGGi" \\ Mardin Artuklu Üniversitesi, Klzıltepe Meslek Yüksekokulu, Bitkisel ve Hayvansal Üretim Bölümü, Mardin, TÜRKIYYE
}

\begin{tabular}{|c|c|}
\hline Geliş Tarihi/Received: 10.07.2019 & Kabul Tarihi/Accepted: 11.02 .2020 \\
\hline \multicolumn{2}{|l|}{ ORCID ID } \\
\hline (1D) orcid.org/0000-0003-1657-1169 & \\
\hline
\end{tabular}

"Sorumlu Yazar/Corresponding Author: necatizgi@hotmail.com

Öz: Bu çalışma; yağ gülü (Rosa damascena Mill.), kadıntuzluğu (Berberis thunbergii DC.), biberiye (Rosmarinus officinalis L.) ve lavanta (Lavandula angustifolia Mill.) bitkilerine ait çeliklerde, farklı köklendirme ortamları [torf, perlit, torf-perlit (1:1) ve kokopit] ve indol-3-bütirik asit (IBA) dozlarının (0, 1000, 2000, 3000, 4000, 5000 ppm) köklenmeye etkilerini saptamak amacıyla yapılmıștır. Celikler, sera ortamında farklı IBA çözeltilerine maruz tutularak dört farklı ortamda dikimleri yapılmıştır. Yaklaşık 80 gün köklendirmeye bırakılan çeliklerde köklenme oranları, kök uzunlukları ve kök sayıları belirlenmiștir. Araștırma sonucunda, köklendirme ortamları ve farklı dozlardaki IBA uygulamalarının yağ gülü, kadıntuzluğu, biberiye ve lavanta çeliklerinde köklenmeye etkisi anlamlı bulunmuştur. Yağ gülü, kadıntuzluğu, biberiye ve lavanta bitkilerinde en yüksek köklenme oranları sırasıyla $\% 95.00, \% 81.67, \% 88.33$ ve $\% 82.50$; kök sayıları sırasıyla 19.28, 13.44, 26.12 ve 17.38 adet bitki ${ }^{-1}$ ve kök uzunlukları sırasıyla $18.89,14.32,25.58$ ve $17.26 \mathrm{~cm}$ ile perlit köklendirme ortamında ve 4000-5000 ppm IBA çözeltisinde olduğu tespit edilmiştir. Bitki çeliklerinin köklendirme ortamı olarak perlit ortamından, IBA dozu olarak ise adventif köklenmeyi teşvik eden 4000 ppm uygulamasından en iyi sonuçlar alınmıştır.

Anahtar Kelimeler: İndol-3-bütirik asit, torf-perlit, köklenme oranı, kök sayısı, kök uzunluğu

\section{Effects of Different Doses of IBA (Indole-3-Butyric Acid) and Rooting Media on Rooting of Some Medicinal Plants}

\begin{abstract}
This study was carried out to determine the effects of different rooting media (peat, perlite, peat-perlite (1:1), and cocopeat) and IBA doses (control, 1000, 2000, 3000, 4000, 5000 ppm) on rooting of damask rose (Rosa damascena Mill.), Thunberg barberry (Berberis thunbergii DC), rosemary (Rosmarinus officinalis L.) and lavender (Lavandula angustifolia Mill.) cuttings. The cuttings were exposed to different indole-3-butyric acid (IBA) solutions in the greenhouse and planted in four different medium. Rooting percentage, root lengths, and the number of the roots were determined for the cuttings which were left to rooting for approximately 80 days. As a result of the study, the effect of rooting medium and different doses of IBA on rooting in damask rose, thunberg barberry, rosemary, and lavender cuttings were found to be statistically significant. The highest rooting percentages for the damask rose, thunberg barberry, rosemary, and lavender were found to be $95.00 \%$, $81.67 \%, 88.33 \%$, and $82.50 \%$; number of roots were $19.28,13.44,26.12$ and 17.38 per plant; and root lengths were 18.89 , $14.32,25.58$ and $17.26 \mathrm{~cm}$, respectively, in perlite rooting medium and 4000-5000 ppm IBA solution. The best results for rooting medium were obtained from perlite and the best results for the IBA dose were obtained from $4000 \mathrm{ppm}$ application that promotes adventitious rooting.
\end{abstract}

Keywords: Indole-3-butyric acid, peat-perlite, rooting percentage, number of roots, root length 


\section{Giriș}

T1bbi ve aromatik bitkiler; baharat ve aroma verici, bitkisel ilaç gıda takviyesi, bitkisel çay ve içecekler, aromaterapi, kozmetik, bitkisel kökenli bitki koruma ilaçları, gıda ve tekstil boyamacılığında, süs ve peyzaj bitkisi olarak değerlendirilebilen bitkilerdir. Doğadan toplama ya da tarla tarımı içerisinde üretimi yapılan bu bitkilerde tohum, soğan, yumru ve çelik gibi çoğaltma organları kullanılmaktadır. Generatif ve vejetatif çoğaltma materyallerinde tohumla üretimde tohum çimlenme sorunları yanı sıra gelişim de yavaş olabilmektedir. Bazı türler steril özellikleri nedeniyle tohum bağlayamamakta ya da çimlenme oranı çok düşük olmaktadır (Baydar, 2009). Çelikle üretim, tıbbi ve aromatik bitkilerin çoğaltılmalarında tohumla üretim gibi kullanılan yaygın yöntem olup; dar bir alanda az miktardaki bireyden fazla sayıda bitki üretimine imkân vermekte; ucuz, hızlı, basit bir teknik olmasının yanı sıra aşı ve mikro üretim tekniklerinde olduğu gibi özel muameleler gerektirmez. Bitki çeliği, materyalinin alındığ 1 anacın aynı genetik özellikleriyle üretimine imkân verir. Başka bir açıdan değerlendirildiğinde ise yabancı döllenen, dolayısıyla hem uçucu yağ açısından hem morfolojik hem de kemotipik varyasyon bu bitkilerde bilinen bir gerçektir. Yabancı döllenen çok yıllık bitkilerde varyasyonu önlemenin en kolay yolu seçilen bitkiler ile klonal çoğaltım yöntemlerini kullanmaktır (Tınmaz ve ark., 2014). T1bbi bitkilerde farklı indol-3-butirik asit (IBA) dozlarının bitkilerde köklenme parametreleri üzerine etkisini belirleyen pek çok çalışma bulunmaktadır (Ünal ve ark., 2004; Özcan ve ark., 2013; Gümüşçü ve Gümüşçü, 2015; Kalyoncu ve ark., 2016). Çelikle üretimde köklendirici hormon kullanımı köklenme yüzdesini arttırmaktadır.

Oksin grubu büyüme düzenleyiciler içerisinde yer alan IBA, dünyadaki en etkili ve yaygın olarak kullanılan kök hormonu olup; IBA, çelikle çoğaltmada köklenmeyi tetikleyebilmektedir. $\mathrm{Bu}$ maddelerin uygulanmasındaki amaç zor köklenen türlerde çeliklerin kök oluşumunu hızlandırmak, çelik başına kök sayısını ve kalitesini artırmaktır (Gerçekcioğlu, 2009; Kalyoncu ve ark., 2016).

Köklendirme ortamı ve köklendirme birimleri hakkında az sayıda çalışma bulunmaktadır. Perlit, çiftçiler tarafından en sık kullanılan köklendirme aracıdır; ancak, peat, kum, vermikülit, saman ve benzeri malzemeler de bu amaçla kullanılabilmektedir (Özcan, 1993; Ercişli ve ark., 2002; Kumar ve Sharma, 2002).

Perlit, yüksek su içeriğine sahip amorf bir volkanik camdır. Bahçecilikte perlit, toprak yapısını değiştirme amaçlı veya topraksız tarım için tek başına kullanılabilir. Mineral veya besin içermez. Torf kısmen çürümüş bitki örtüsünden oluşmakta; diğer birçok bitkiyi bünyesinde bulundursa da, en yaygın bileşeni sfagnum yosunudur. Torf; ağırlığının 20 katına kadar su tutabilmekte, pH derecesi 6-7 arasında değişmekte, \% 80 oranında organik madde, ortalama olarak $\% 1$ organik azot ve $\% 46$ organik karbon içermektedir. Bitki çeliklerinde toprak yerine yaygın olarak tercih edilir. Kokopit; Hhindistan cevizi özü, Hindistan cevizi lifi, Hindistan cevizi tozu veya basitçe Hindistancevizi olarak da bilinir. Hindistancevizi kabuklarından yapılır ve hindistancevizi kullanan diğer endüstrilerin bir yan ürünüdür. Kokopit, toprak katkı maddesi olarak kullanılır. Düşük seviyelerde besin içerir ve bu nedenle genellikle bitki yetiştiriciliği için kullanılan ortamdaki tek bileşen değildir. Genellikle asidik $(\mathrm{pH}=5.5-6.5)$ yapıdadır. En önemli özelliği, hacminin 8-9 katı su tutmasıdır (Hartmann ve Kester, 1983).

Dumitrascu ve ark. (2003) farklı köklendirme ortamlarında yaptıkları çalışmada, Chamaecyparis pisifera ve Juniperus chinensis'in kök çeliklerinde en yüksek köklenme yüzdesinin (sırasıyla \% 96 ve 82) kum + yaprak (2: 1) kompostunda olduğunu belirtmişlerdir. Sevik ve ark. (2015); beşparmak (Schefflera arboricola) türünde kum, perlit ve turba ortamlarının köklenme oranını \% 75'e kadar artırılabildiğini belirtmişlerdir.

$\mathrm{Bu}$ çalışmanın amacı; farklı köklendirme ortamlarında ve farklı köklendirme hormonu (IBA) seviyelerinde yağ gülü (Rosa damascena Mill.), kadıntuzluğu (Berberis thunbergii DC.), biberiye (Rosmarinus officinalis L.) ve lavanta (Lavandula angustifolia Mill.) bitkilerinin köklenme oran1, kök sayıs1 ve kök uzunluğu üzerine etkilerinin belirlenmesidir.

\section{Materyal ve Yöntem}

Mardin Büyükşehir Belediyesi serasında yürütülen bu çalışmada; belediye fidanlığında yetiştirilen yağ gülü ( $R$. damascena), kadıntuzluğu (B. thunbergii), biberiye ( $R$. officinalis) ve lavanta ( $L$. angustifolia)'nın bir yıllık sürgün çelikleri kullanılmıştır. Çalışmada, 2017 vejetasyon döneminde, Şubat ayı sonunda çelikler her bitki grubundan 10-12 cm uzunluğunda bitki başına 720 adet bitki çeliği hazırlanmıştır. Her bir tür için çelikleri dört farklı köklendirme ortamı ve altı farklı IBA çözeltisi olmak üzere toplam 24 grup oluşturulmuş, her grupta 30 adet çelik bulundurulmuştur.

Çeliklerin 3-4 cm'lik kısmı çözeltiye daldırılmıştır. Bitki çelikleri 30’arlı gruplar halinde, büyüme hormonu olarak kullanılan indol-3 bütrik asitin içinde, 5 grup 5'er saniye bekletilmiş 
(kronometre kullanılarak) ve bir grup ise IBA uygulanmadan köklendirme ortamına alınmıştır. IBA çözeltileri 1000, 2000, 3000, 4000, 5000 ppm ve kontrol grubu olmak üzere çelikler 6 farklı uygulamaya maruz bırakılmıştır. Köklendirme ortamlar1; torf, perlit, kokopit ve torf-perlit $(1: 1)$ karışımı olmak üzere 4 gruptur. Köklendirme ortamlar1 olarak, önceden serada hazır olan tavalarda uygulamalar yapılmıştır. Çelikler düzenli olarak sisleme başlığıyla sulanmıştır. Sıcaklık, elektrikli infrared isiticilarla $25{ }^{\circ} \mathrm{C}$ 'de sabit tutulmuş (Kara ve ark. 2011) ve köklendirme uygulamasının 80'inci gününde çelikler sökülerek köklenme oranı (\%), kök sayısı (adet) ve kök uzunluğu $(\mathrm{cm})$ değerleri belirlenmiştir.

Araştırmada, denemeler tesadüf parselleri deneme desenine göre 3 tekerrürlü olarak kurulmuştur. Elde edilen verilerin istatistiksel analizleri JMP 5.0 Programı kullanılarak yapılmış ve önem derecelerine göre ortalamalar arasındaki farklılığın belirlenmesinde Asgari Önemli Fark (AÖF) Testi uygulanmıştır.

\section{Bulgular}

\subsection{Yağ gülü (R. damascena Mill.)}

Yağ gülü bitkisinde kök sayısı yönünden, IBA dozu $\mathrm{x}$ köklendirme ortamı interaksiyonu istatistiksel olarak önemli $(\mathrm{p}<0.05)$ bulunmuştur. En yüksek kök sayısı 4000 ppm IBA dozunda perlit köklendirme ortamından (23.62 adet) elde edilirken, en düşük kök sayısı hormon uygulanmayan torf ortamından (9.98 adet) elde edilmiştir. Yağ gülü çeliklerinin kök sayısına, hormon dozları ile farklı köklendirme ortamlarının etkisi istatistiksel olarak çok önemli $(p<0.01)$ olmuştur. En yüksek kök sayısı değeri köklendirme ortamlarının ortalaması olarak 19.28 adet ile 4000 ppm IBA uygulamasından elde edilirken, en düşük değer IBA uygulamasının yapılmadığı kontrol grubunda (11.46 adet) saptanmıştır. Köklendirme ortamlarının kök sayısına etkisi tek başına gözden geçirildiğinde, IBA dozlarının ortalaması olarak en yüksek kök sayısı değeri 18.66 adet ile perlit ortamında köklendirilen yağ gülü çeliklerinden elde edilmiştir. Kök sayısı yönünden torf ortamı en düşük değerleri (13.21 adet) göstermiştir (Tablo 1).

Yağ gülü çeliklerinin kök uzunluğuna, hormon dozları ile farklı köklendirme ortamlarının etkisi istatistiksel olarak çok önemli olmuştur $(p<0.01)$. Hormon dozları incelendiğinde, en yüksek kök uzunluğu değeri köklendirme ortamlarının ortalaması olarak $18.89 \mathrm{~cm}$ ile $4000 \mathrm{ppm}$ IBA dozunda elde edilmiş, kök uzunluğu yönünden bu doz ile 3000 ppm IBA uygulama dozu arasındaki farklılık istatistiki olarak önemsiz bulunmuştur. En

Tablo 1. Yağ gülü çeliklerinin köklenmesi üzerine farklı köklendirme ortamı ve IBA dozlarının etkisi*

\begin{tabular}{|c|c|c|c|c|c|}
\hline \multirow{3}{*}{ IBA (ppm) } & \multicolumn{5}{|c|}{ Köklendirme ortamı } \\
\hline & Torf & Perlit & Kokopit & Torf/Perlit (1:1) & Ortalama \\
\hline & \multicolumn{5}{|c|}{ Kök sayısı (adet çelik $\left.{ }^{-1}\right)$} \\
\hline 0 & $9.98 \mathrm{q}$ & $13.62 \mathrm{~km}$ & $11.74 \mathrm{nq}$ & $10.48 \mathrm{pq}$ & $11.46 \mathrm{D}$ \\
\hline 1000 & $12.15 \mathrm{mp}$ & $16.14 \mathrm{fj}$ & $14.36 \mathrm{jl}$ & 12.84 lo & $13.87 \mathrm{CD}$ \\
\hline 2000 & $13.26 \ln$ & $19.10 \mathrm{bc}$ & $16.08 \mathrm{fj}$ & $15.12 \mathrm{kk}$ & $15.89 \mathrm{BC}$ \\
\hline 3000 & $16.03 \mathrm{gj}$ & $20.37 \mathrm{~b}$ & $18.23 \mathrm{ce}$ & $17.62 \mathrm{cg}$ & $18.06 \mathrm{AB}$ \\
\hline 4000 & $16.59 \mathrm{e} 1$ & $23.62 \mathrm{a}$ & $19.06 \mathrm{bd}$ & $17.85 \mathrm{cf}$ & $19.28 \mathrm{~A}$ \\
\hline 5000 & $11.27 \mathrm{og}$ & $19.10 \mathrm{bc}$ & $17.27 \mathrm{dh}$ & $15.61 \mathrm{hj}$ & $15.81 \mathrm{BC}$ \\
\hline \multirow[t]{2}{*}{ Ortalama } & $13.21 \mathrm{D}$ & $18.66 \mathrm{~A}$ & $16.12 \mathrm{~B}$ & $14.92 \mathrm{C}$ & \\
\hline & \multicolumn{5}{|c|}{ Kök uzunluğu (cm) } \\
\hline 0 & 10.43 & 15.03 & 13.32 & 11.94 & $12.68 \mathrm{C}$ \\
\hline 1000 & 11.27 & 16.03 & 14.03 & 12.21 & $13.39 \mathrm{C}$ \\
\hline 2000 & 13.17 & 19.39 & 16.39 & 15.38 & $16.08 \mathrm{~B}$ \\
\hline 3000 & 15.76 & 19.73 & 18.49 & 16.90 & $17.72 \mathrm{AB}$ \\
\hline 4000 & 16.29 & 21.36 & 19.43 & 18.47 & $18.89 \mathrm{~A}$ \\
\hline 5000 & 13.00 & 21.30 & 18.08 & 16.20 & $17.14 \mathrm{~B}$ \\
\hline \multirow[t]{2}{*}{ Ortalama } & $18.81 \mathrm{~A}$ & $16.62 \mathrm{~B}$ & $15.19 \mathrm{C}$ & $13.32 \mathrm{D}$ & \\
\hline & \multicolumn{5}{|c|}{ Köklenme oranı (\%) } \\
\hline 0 & 46.67 & 66.67 & 56.67 & 53.33 & $55.83 \mathrm{C}$ \\
\hline 1000 & 73.33 & 86.67 & 83.33 & 80.00 & $80.83 \mathrm{~B}$ \\
\hline 2000 & 83.33 & 86.67 & 86.67 & 83.33 & $85.00 \mathrm{AB}$ \\
\hline 3000 & 90.00 & 100.00 & 96.67 & 93.33 & $95.00 \mathrm{~A}$ \\
\hline 4000 & 93.33 & 96.67 & 96.67 & 93.33 & $95.00 \mathrm{~A}$ \\
\hline 5000 & 80.00 & 90.00 & 83.33 & 83.33 & $84.17 \mathrm{~B}$ \\
\hline Ortalama & $77.78 \mathrm{C}$ & $87.78 \mathrm{~A}$ & $83.89 \mathrm{~B}$ & $81.11 \mathrm{~B}$ & \\
\hline
\end{tabular}

*: Aynı grupta aynı harfle gösterilen ortalamalar arasındaki farklılık istatistiki açıdan önemli değildir. 
düşük kök uzunluğu değerleri ise 0 ve 1000 ppm IBA uygulamalarında (sırasıyla, $12.68 \mathrm{~cm}$ ve 13.39 $\mathrm{cm})$ belirlenmiştir. Çalışmada, torf ortamındaki yağ gülü çeliklerinden en uzun kök uzunluğu değeri $(18.81 \mathrm{~cm}$ ) elde edilmiştir (Tablo 1).

Köklenme oranı üzerine kök uzunluğunda olduğu gibi IBA dozlarının ve köklendirme ortamlarının etkisi çok önemli $(p<0.01)$ olmuştur. En yüksek köklenme oranı 3000 ve 4000 ppm IBA dozlarından (\% 95.00) elde edilirken, en düşük köklenme oranı kontrol uygulamasında (\% 55.83) tespit edilmiştir. Köklenme oranı yönünden perlit köklendirme ortamında en yüksek sonuçlar (\% 87.78) elde edilirken, torf ortamı en düşük değeri (\% 77.78) göstermiştir (Tablo 1).

\subsection{Kadıntuzluğu (B. thunbergii DC.)}

Kadıntuzluğu bitkisinde kök sayısı yönünden, IBA dozu $\mathrm{x}$ köklendirme ortamı interaksiyonu istatistiksel olarak çok önemli $(p<0.01)$ bulunmuştur. En yüksek kök sayısı, 3000 ppm IBA dozunda ve perlit köklendirme ortamından (15.21 adet çelik ${ }^{-1}$ ) elde edilirken, en düşük kök sayıs1 hormon uygulanmayan kokopit ortamından (6.85 adet çelik ${ }^{-1}$ ) elde edilmiştir. Farklı IBA dozlarında kadıntuzluğu çeliklerinin köklenmesinde, kök sayısı ortalamaları arasındaki farklılık istatistiki açıdan çok önemli olup ( $\mathrm{p}<0.01)$; en yüksek değer 3000 ppm IBA dozunda (13.44 adet çelik $\left.{ }^{-1}\right)$ belirlenmiş, bunu 13.23 adet çelik ${ }^{-1}$ ile 2000 ve
11.81 adet çelik $^{-1}$ ile 4000 ppm IBA uygulama konuları takip etmiştir. En az kök sayısı ise kontrolden (7.39 adet çelik ${ }^{-1}$ ) elde edilmiştir. Kök sayıs1 yönünden, köklendirme ortamları arasındaki farkl11ı istatistiki açıdan $\mathrm{p}<0.01$ düzeyinde önemli bulunmuş; en yüksek değerler IBA dozlarının ortalaması olarak 12.53 adet çelik ${ }^{-1}$ ile perlit ortamından elde edilmiştir (Tablo 2).

Kök uzunluğu incelendiğinde, IBA dozları ortalamaları arasındaki farklılık istatistiksel olarak çok önemli olup $(\mathrm{p}<0.01)$; köklendirme ortamının ortalaması olarak en yüksek değerler; 4000 ve 5000 ppm IBA dozlarında (sırasiyla, $13.82 \mathrm{~cm}$ ve 14.32 $\mathrm{cm}$ ), en düşük kök uzunluğu ortalaması ise $7.46 \mathrm{~cm}$ ile kontrol uygulamasında kaydedilmiştir. Çalışmada, kök uzunluğu yönünden, köklendirme ortamları arasındaki farklılık istatistiki açıdan $\mathrm{p}<0.01$ düzeyinde önemli bulunmuş; en yüksek değerler IBA dozlarının ortalaması olarak $12.76 \mathrm{~cm}$ ile yine perlit ortamından elde edilmiştir (Tablo 2).

Köklenme oranı açısından köklendirme ortamlarının etkisi istatistiki olarak çok önemli $(p<0.01)$ olup, en yüksek köklenme oranı \% 76.67 ile perlit ortamından elde edilirken, en düşük köklenme oranı \% 68.89 ile torf ortamından elde edilmiştir. Farklı IBA dozlarının köklenme oranı üzerine etkisi istatistiksel olarak önemsiz olup, IBA dozlarına göre köklenme oranı \% 57.50-\% 81.67 arasında değişim göstermiştir (Tablo 2).

Tablo 2. Kadıntuzluğu çeliklerinin köklenmesi üzerine farklı köklendirme ortamı ve IBA dozlarının etkisi*

\begin{tabular}{|c|c|c|c|c|c|}
\hline \multirow{3}{*}{ IBA (ppm) } & \multicolumn{5}{|c|}{ Köklendirme ortamı } \\
\hline & Torf & Perlit & Kokopit & Torf/Perlit $(1: 1)$ & Ortalama \\
\hline & \multicolumn{5}{|c|}{ Kök sayısı (adet çelik $\left.{ }^{-1}\right)$} \\
\hline 0 & $8.31 \mathrm{kl}$ & 7.211 & 6.851 & 7.171 & $7.39 \mathrm{C}$ \\
\hline 1000 & $9.17 \mathrm{k}$ & $11.40 \mathrm{e} 1$ & $10.55 \mathrm{fj}$ & $9.96 \mathrm{k}$ & $10.27 \mathrm{~B}$ \\
\hline 2000 & $10.91 \mathrm{e} 1$ & $14.38 \mathrm{ab}$ & $13.44 \mathrm{bd}$ & $14.19 \mathrm{ab}$ & $13.23 \mathrm{~A}$ \\
\hline 3000 & $12.56 \mathrm{ce}$ & $15.21 \mathrm{a}$ & $13.99 \mathrm{ac}$ & $12.00 \mathrm{dg}$ & $13.44 \mathrm{~A}$ \\
\hline 4000 & $10.24 \mathrm{hj}$ & $14.78 \mathrm{ab}$ & $11.80 \mathrm{dh}$ & $10.43 \mathrm{gj}$ & $11.81 \mathrm{AB}$ \\
\hline 5000 & $9.761 \mathrm{k}$ & $12.19 \mathrm{df}$ & $10.85 \mathrm{f1}$ & $10.51 \mathrm{gj}$ & $10.83 \mathrm{~B}$ \\
\hline \multirow[t]{2}{*}{ Ortalama } & $10.16 \mathrm{C}$ & $12.53 \mathrm{~A}$ & $11.25 \mathrm{~B}$ & $10.71 \mathrm{BC}$ & \\
\hline & \multicolumn{5}{|c|}{ Kök uzunluğu (cm) } \\
\hline 0 & 7.04 & 8.74 & 8.02 & 6.03 & $7.46 \mathrm{C}$ \\
\hline 1000 & 10.34 & 10.28 & 8.79 & 8.81 & $9.56 \mathrm{BC}$ \\
\hline 2000 & 9.44 & 11.81 & 11.30 & 10.38 & $10.73 \mathrm{~B}$ \\
\hline 3000 & 10.32 & 12.79 & 12.62 & 10.62 & $11.59 \mathrm{~B}$ \\
\hline 4000 & 10.94 & 16.09 & 14.39 & 13.83 & $13.82 \mathrm{~A}$ \\
\hline 5000 & 12.95 & 16.84 & 14.19 & 13.30 & $14.32 \mathrm{~A}$ \\
\hline \multirow[t]{2}{*}{ Ortalama } & $10.17 \mathrm{C}$ & $12.76 \mathrm{~A}$ & $11.55 \mathrm{~B}$ & $10.50 \mathrm{C}$ & \\
\hline & \multicolumn{5}{|c|}{ Köklenme oranı (\%) } \\
\hline 0 & 50.00 & 66.67 & 56.67 & 56.67 & 57.50 \\
\hline 1000 & 73.33 & 86.67 & 83.33 & 80.00 & 80.83 \\
\hline 2000 & 63.33 & 70.00 & 66.67 & 63.33 & 65.83 \\
\hline 3000 & 80.00 & 83.33 & 80.00 & 83.33 & 81.67 \\
\hline 4000 & 70.00 & 80.00 & 66.67 & 66.67 & 70.83 \\
\hline 5000 & 76.67 & 73.33 & 76.67 & 73.33 & 75.00 \\
\hline Ortalama & $68.89 \mathrm{~B}$ & $76.67 \mathrm{~A}$ & $71.67 \mathrm{~B}$ & $70.56 \mathrm{~B}$ & \\
\hline
\end{tabular}

\footnotetext{
": Aynı grupta aynı harfle gösterilen ortalamalar arasındaki farklılık istatistiki açıdan önemli değildir.
} 


\subsection{Biberiye ( $R$. officinalis $L$.)}

Biberiye türünde yapılan çelik köklendirme çalışmaları sonucunda elde edilen bulgulara göre; kök sayısı yönünden, IBA dozu x köklendirme ortamı interaksiyonu istatistiksel olarak çok önemli çıkmıştır $(\mathrm{p}<0.01)$. Bitki çeliklerinde en yüksek kök sayıs 5000 ppm IBA dozunda torf köklendirme ortamından (32.63 adet çelik ${ }^{-1}$ ) elde edilirken, en düşük kök sayısı hormon uygulanmayan kokopit ortamından (11.28 adet çelik $\left.{ }^{-1}\right)$ elde edilmiştir (Tablo 3).

Kök sayısı konusunda, köklendirme ortamları ve IBA doz uygulamalarının etkileri istatistiki açıdan çok önemli $(p<0.01)$ bulunmuştur. IBA uygulamaları yönünden en yüksek kök sayıs1 ortalaması $5000 \mathrm{ppm}$ IBA dozundan (26.12 adet çelik ${ }^{-1}$ ) elde edilirken, en düşük kök sayısı ortalaması kontrol grubunda (13.01 adet çelik ${ }^{-1}$ ) elde edilmiștir. Köklendirme ortamları bakımından en yüksek kök sayısı perlit ortamında (23.96 adet çelik ${ }^{-1}$ ) elde edilirken, en düşük kök sayısı torf köklenme ortamında (17.44 adet çelik $\left.{ }^{-1}\right)$ saptanmıştır (Tablo 3).

Kök uzunluğu ortalamaları açısından; en yüksek kök uzunluğu değeri 4000 ppm IBA dozu uygulamasında $(22.58 \mathrm{~cm})$, en düşük kök uzunluğu değeri ise 1000 ppm IBA uygulamasında (20.24 $\mathrm{cm}$ ) elde edilmiştir. Farklı köklenme ortamlarından elde edilen kök uzunluğu ortalaması en yüksek perlitte $(25.10 \mathrm{~cm})$, en düşük kök uzunluğu $(17.87$ $\mathrm{cm})$ ise torf köklendirme ortamindan elde edilmiştir. Kök uzunluğu yönünden IBA dozları ve köklendirme ortamları arasındaki bu farklı1ık istatistiki açıdan çok önemli $(\mathrm{p}<0.01)$ bulunmuştur (Tablo 3).

Farklı IBA dozlarında köklenme oran ortalamaları; en düşük \% 62.50 ile kontrol uygulamasından, en yüksek köklenme oranları $\% 88.33$ ve $\% 86.67$ ile sirasiyla 4000 ve 5000 ppm IBA dozlarından elde edilmiştir. Farklı köklendirme ortamlarında köklenme oranı ortalamaları; en iyi sonuç perlit köklendirme ortamından ( $\%$ 82.78), en düşük sonuç torf ortamından (\% 72.78) elde edilmiștir. Köklenme oranı yönünden IBA dozları ve köklendirme ortamları arasındaki bu farklılık istatistiki açıdan çok önemli $(\mathrm{p}<0.01)$ bulunmuştur (Tablo 3 ).

\subsection{Lavanta (L. angustifolia Mill.)}

Lavanta çeliklerinde kök sayısı değerleri incelendiğinde, farklı hormon dozları çelik başına kök sayısı ortalamalarını önemli derecede $(\mathrm{p}<0.05)$, köklendirme ortamları ise çok önemli derecede $(p<0.01)$ etkilemiştir. En fazla kök sayısı ortalaması 4000 ppm IBA dozundan (17.38 adet çelik $\left.{ }^{-1}\right)$, en düşük kök sayısı ise 5000 ppm IBA dozundan

Tablo 3. Biberiye çeliklerinin köklenmesi üzerine farklı köklendirme ortamı ve IBA dozlarının etkisi*

\begin{tabular}{|c|c|c|c|c|c|}
\hline \multirow{3}{*}{ IBA (ppm) } & \multicolumn{5}{|c|}{ Köklendirme ortamı } \\
\hline & Torf & Perlit & Kokopit & Torf/Perlit (1:1) & Ortalama \\
\hline & \multicolumn{5}{|c|}{ Kök sayısı (adet çelik $\left.{ }^{-1}\right)$} \\
\hline 0 & $15.52 \mathrm{jk}$ & $13.21 \mathrm{~km}$ & $11.28 \mathrm{~m}$ & $12.02 \mathrm{~lm}$ & $13.01 \mathrm{C}$ \\
\hline 1000 & $19.33 \mathrm{gh}$ & $16.44 \mathrm{ij}$ & $14.22 \mathrm{j} 1$ & $15.47 \mathrm{jk}$ & $16.37 \mathrm{BC}$ \\
\hline 2000 & $25.19 \mathrm{c}$ & $23.29 \mathrm{~cd}$ & $18.48 \mathrm{~h} 1$ & $20.16 \mathrm{fh}$ & $21.78 \mathrm{~B}$ \\
\hline 3000 & $25.43 \mathrm{c}$ & $24.43 \mathrm{~cd}$ & $19.14 \mathrm{gh}$ & $22.19 \mathrm{df}$ & $22.80 \mathrm{~B}$ \\
\hline 4000 & $25.62 \mathrm{c}$ & $23.78 \mathrm{~cd}$ & $20.91 \mathrm{eg}$ & $20.34 \mathrm{eh}$ & $22.67 \mathrm{~B}$ \\
\hline 5000 & $32.63 \mathrm{a}$ & $28.74 \mathrm{~b}$ & $20.60 \mathrm{eh}$ & $22.52 \mathrm{de}$ & $26.12 \mathrm{~A}$ \\
\hline \multirow[t]{2}{*}{ Ortalama } & $17.44 \mathrm{D}$ & $23.96 \mathrm{~A}$ & $21.65 \mathrm{~B}$ & $18.79 \mathrm{C}$ & \\
\hline & \multicolumn{5}{|c|}{ Kök uzunluğu (cm) } \\
\hline 0 & 18.28 & 24.14 & 20.68 & 19.28 & $20.59 \mathrm{CD}$ \\
\hline 1000 & 15.39 & 24.28 & 22.02 & 19.27 & $20.24 \mathrm{D}$ \\
\hline 2000 & 18.86 & 24.31 & 22.41 & 20.41 & $21.50 \mathrm{BC}$ \\
\hline 3000 & 16.70 & 26.84 & 23.61 & 21.29 & $22.11 \mathrm{AB}$ \\
\hline 4000 & 19.34 & 25.48 & 23.29 & 22.22 & $22.58 \mathrm{~A}$ \\
\hline 5000 & 18.68 & 25.58 & 21.74 & 20.00 & $21.50 \mathrm{BC}$ \\
\hline \multirow[t]{2}{*}{ Ortalama } & $17.87 \mathrm{D}$ & $25.10 \mathrm{~A}$ & $22.29 \mathrm{~B}$ & $20.41 \mathrm{C}$ & \\
\hline & \multicolumn{5}{|c|}{ Köklenme oranı (\%) } \\
\hline 0 & 60.00 & 66.67 & 63.33 & 60.00 & $62.50 \mathrm{C}$ \\
\hline 1000 & 70.00 & 80.00 & 73.33 & 70.00 & $73.33 \mathrm{~B}$ \\
\hline 2000 & 70.00 & 76.67 & 76.67 & 76.67 & $75.00 \mathrm{~B}$ \\
\hline 3000 & 76.67 & 83.33 & 86.67 & 83.33 & $82.50 \mathrm{AB}$ \\
\hline 4000 & 83.33 & 93.33 & 90.00 & 86.67 & $88.33 \mathrm{~A}$ \\
\hline 5000 & 76.67 & 96.67 & 90.00 & 83.33 & $86.67 \mathrm{~A}$ \\
\hline Ortalama & $72.78 \mathrm{C}$ & $82.78 \mathrm{~A}$ & $80.00 \mathrm{AB}$ & $76.67 \mathrm{BC}$ & \\
\hline
\end{tabular}

\footnotetext{
*: Aynı grupta aynı harfle gösterilen ortalamalar arasındaki farklılık istatistiki açıdan önemli değildir.
} 
(11.13 adet çelik ${ }^{-1}$ ) ve kontrol uygulamasından (11.46 adet çelik ${ }^{-1}$ ) elde edilmiştir. Köklendirme ortamında ise en iyi sonuç perlit köklendirme ortamından (18.87 adet çelik $\left.{ }^{-1}\right)$, en düşük sonuç torf ortamından (10.23 adet çelik $^{-1}$ ) elde edilmiştir (Tablo 4).

Lavantanın kök uzunluğu; artan hormon dozları ile birlikte artarak 4000 ppm dozunda en yüksek değere $(17.26 \mathrm{~cm})$ ulaşmış, bu dozdan sonra istatistiki olarak anlamlı düşüş göstermiş ve 5000 ppm dozu $(12.53 \mathrm{~cm})$ kontrol konusu ile $(12.34 \mathrm{~cm})$ en düşük değerleri vermiştir. Kök uzunluğu yönünden IBA dozları arasındaki bu farklılık istatistiki açıdan çok önemli $(p<0.01)$ bulunmuştur. Köklendirme ortamı kök uzunluğunu istatistiki açıdan çok önemli $(\mathrm{p}<0.01)$ derecede etkilemiş, en yüksek kök uzunluğu perlit ortamından elde edilirken $(18.66 \mathrm{~cm})$, en düşük torf ortamından $(11.64 \mathrm{~cm})$ elde edilmiştir (Tablo 4).

Köklenme oranı yönünden, lavanta bitki çeliklerinde IBA dozları arasında en yüksek değerler 4000 ppm IBA dozundan (\% 82.50) elde edilirken, en düşük kontrol uygulamasından $\left(\begin{array}{ll}\% & 50.83\end{array}\right)$ elde edilmiştir. Köklendirme ortamlarında köklenme oranı ortalamaları; en yüksek perlit ortamında (\% 78.33), en düşük oran ise torf ortaminda ( $\%$ 63.33) olduğu tespit edilmiştir. Köklenme oranı üzerine, IBA dozları ve köklendirme ortamlarının bu etkileri istatistiki açıdan çok önemli $(\mathrm{p}<0.01)$ bulunmuştur (Tablo 4).

Tablo 4. Lavanta çeliklerinin köklenmesi üzerine farklı köklendirme ortamı ve IBA dozlarının etkisi*

\begin{tabular}{|c|c|c|c|c|c|}
\hline \multirow{3}{*}{ IBA (ppm) } & \multicolumn{5}{|c|}{ Köklendirme ortamı } \\
\hline & Torf & Perlit & Kokopit & Torf/Perlit $(1: 1)$ & Ortalama \\
\hline & \multicolumn{5}{|c|}{ Kök sayısı (adet çelik $\left.{ }^{-1}\right)$} \\
\hline 0 & 8.00 & 18.67 & 9.45 & 9.70 & $11.46 \mathrm{C}$ \\
\hline 1000 & 7.94 & 19.98 & 11.90 & 11.12 & $12.74 \mathrm{BC}$ \\
\hline 2000 & 11.43 & 17.07 & 12.82 & 11.23 & $13.13 \mathrm{BC}$ \\
\hline 3000 & 10.37 & 17.97 & 14.50 & 12.84 & $13.92 \mathrm{~B}$ \\
\hline 4000 & 14.79 & 22.30 & 16.44 & 15.98 & $17.38 \mathrm{~A}$ \\
\hline 5000 & 8.85 & 17.24 & 8.83 & 9.59 & $11.13 \mathrm{C}$ \\
\hline \multirow[t]{2}{*}{ Ortalama } & $10.23 \mathrm{C}$ & $18.87 \mathrm{~A}$ & $12.32 \mathrm{~B}$ & $11.74 \mathrm{BC}$ & \\
\hline & \multicolumn{5}{|c|}{ Kök uzunluğu (cm) } \\
\hline 0 & 8.51 & 17.46 & 10.68 & 12.69 & $12.34 \mathrm{C}$ \\
\hline 1000 & 11.06 & 20.33 & 11.75 & 10.99 & $13.53 \mathrm{BC}$ \\
\hline 2000 & 13.40 & 17.16 & 13.19 & 13.21 & $14.24 \mathrm{BC}$ \\
\hline 3000 & 12.48 & 19.12 & 14.75 & 14.96 & $15.33 \mathrm{AB}$ \\
\hline 4000 & 15.59 & 20.26 & 17.12 & 16.08 & $17.26 \mathrm{~A}$ \\
\hline 5000 & 8.82 & 17.65 & 10.66 & 12.97 & $12.53 \mathrm{C}$ \\
\hline \multirow[t]{2}{*}{ Ortalama } & $11.64 \mathrm{C}$ & $18.66 \mathrm{~A}$ & $13.02 \mathrm{~B}$ & $13.48 \mathrm{~B}$ & \\
\hline & \multicolumn{5}{|c|}{ Köklenme oranı (\%) } \\
\hline 0 & 43.33 & 60.00 & 46.67 & 53.33 & $50.83 \mathrm{D}$ \\
\hline 1000 & 53.33 & 76.67 & 63.33 & 53.33 & $61.67 \mathrm{CD}$ \\
\hline 2000 & 63.33 & 73.33 & 73.33 & 63.33 & $68.33 \mathrm{BC}$ \\
\hline 3000 & 66.67 & 86.67 & 73.33 & 73.33 & $75.00 \mathrm{ABC}$ \\
\hline 4000 & 80.00 & 93.33 & 80.00 & 76.67 & $82.50 \mathrm{~A}$ \\
\hline 5000 & 73.33 & 80.00 & 76.67 & 76.67 & $76.67 \mathrm{AB}$ \\
\hline Ortalama & $63.33 \mathrm{C}$ & $78.33 \mathrm{~A}$ & $68.89 \mathrm{~B}$ & $66.11 \mathrm{BC}$ & \\
\hline
\end{tabular}

\section{Tartışma ve Sonuç}

Güneş ve Şen (2001) bazı kuşburnu tiplerinin çelikle çoğaltılmasında, IBA konsantrasyonlarına göre en yüksek ortalama köklenme oranının (\% 36.22) 2000 ppm IBA konsantrasyonundan elde ederlerken, kontrol grubunun ortalama köklenme oranını \% 16.33 olarak belirlemişlerdir. Alp ve ark. (2010) farklı Rosa türlerinin çelikle çoğaltma imkanlarını belirlemeye çalıştıkları araştırmalarında ise; odun çeliklerinde en yüksek köklenme oranı (\% 53.3) 2000 ppm IBA uygulanan $R$. chinensis var. minima çeliklerinden elde edildiğini, $R . x$ damascena var. semperflorens türüne ait odun çeliklerinde ise yine 2000 ppm uygulaması ile köklenme oranının \% 42'ye ulaştı̆̆ını, R. x damascena, R. laxa var. harputensis, $R$. alba semiplena ve $R$. hemispharica türlerinde ise hormon uygulamasına rağmen oldukça düşük oranda köklenme olduğunu bildirmişlerdir.

R. damascena Mill. bitki çeliklerinin farklı IBA dozlarıyla yaptığımız çalışmadan elde ettiğimiz sonuçların yukarıda bahsedilen önceki çalışmalardan farklı olmasının en önemli nedeni, bitki çeliklerinin daha yüksek dozda IBA çözeltisine (5000 ppm) maruz bırakılmaları olarak gösterilebilir. 
Saffari ve Saffari (2012) kadıntuzluğu gibi çok yıllık çalı formunda olan Dodoneae viscosa (Dodenya) türünde çelikle çoğaltmada en iyi sonucun 4000 ppm IBA dozunda perlit köklendirme ortamından alınabileceğini bildirmiştir. Çalışmada kadıntuzluğunda en yüksek kök sayıs1, kök uzunluğu ve kök oranında sırasıyla; 2000-3000 ppm, 5000 ppm ve 3000 ppm IBA dozunda elde edilmiştir.

Kara ve ark. (2011), biberiyede en yüksek köklenme oranını \% 85.0, kök sayısını 28.8 adet bitki $^{-1}$ ve kök uzunluğunu $7.1 \mathrm{~cm}$ olarak 4000 ppm IBA dozunda tespit etmişlerdir. Gudeva ve ark. (2017), biberiyede IBA hormon uygulamasinın diğer ticari hormonlara göre [IAA (Indol-3-Asetik Asit) ve NAA (Naftalen Asetik Asit)] daha etkili olduğunu, alınan çeliklerde, çelik uzunluğu (25.17 $\mathrm{cm})$, köklenen çelik sayısı (46 adet) ve köklenme oranının (\% 92) diğer uygulamalarla (IAA ve NAA) karşılaştırıldığında önemli derecede yüksek olduğunu bildirmişlerdir. Bayraktar ve ark. (2018) Taxus baccata türünde çelikle çoğaltmada en yüksek köklenme oranının 5000 ppm IBA dozunda ve perlit köklendirme ortamından alınabileceğini bildirmişlerdir.

Biberiyenin en yüksek köklenme oranı (\% 88.33), en yüksek kök sayısı (26.12 adet) değerleri Kara ve ark. (2011)'nın bildirdikleriyle paralellik göstermektedir, fakat bununla birlikte çalışmada ölçülen en yüksek kök uzunluğu değeri $(22.58 \mathrm{~cm}) \quad$ Kara ve ark. (2011)'nın bildirdiklerinden oldukça yüksektir.

Ayanoğlu ve ark. (2000) Lavandula stoechas türünde en iyi köklenme oranını \% 70.0 ile 4000 ppm IBA dozunda elde ettiklerini bildirmișlerdir. Özcan ve ark. (2013) farklı IBA dozlarının lavanta bitkilerinin köklendirme çalışmalarında kaliteli köklenme ve köklenen çelik oranı bakımından uygulanabileceğini, Lavanta (Lavandula hybrida) çelikleri üzerine perlit, torf, tarla toprağı gibi üç farklı köklendirme ortamları ile 500, 1000, 2000 ve 4000 ppm IBA dozlarının ve ticari köklendirme maddesi kullanılan bitkilerin kontrol çeliklerine göre kök sayısı, kök uzunluğu, köklenme oranı ve köklenme kalitesini arttırdığını, köklenme oranı bakımından ortamlarla dozlar arasında önemli bir fark görülmemesine rağmen kontrol çelikleriyle kıyaslandığında lavantada 2000 ve 4000 ppm IBA dozlarında ve ticari köklenme tozlarında çeliklerin çoğunun (sırasıyla \% 76.25, \% 87.50, \% 83.75) köklendiğini bildirmişlerdir.

Değişik lavanta türlerinde bitki çeliklerinin farklı IBA dozları ve köklenme ortamlarıyla ilgili yapılmış olan önceki çalışmalar ve bu çalışmada lavanta çeliklerinden elde edilen değerler gösteriyor ki artan IBA dozlarına (maksimum 4000 ppm doza kadar) paralel olarak köklenme değerlerinde de artışlar meydana gelmektedir.

Yağ gülü ( $R$. damascena Mill.), kadıntuzluğu (B. thunbergii DC.), biberiye (R. officinalis Mill.) ve lavanta (L. angustifolia L.) bitki çeliklerinde, farklı köklendirme ortamları [torf, perlit, torf-perlit (1:1) ve kokopit] ve IBA oranlarının (kontrol, 1000, 2000, 3000, 4000, 5000 ppm) köklenmeye etkilerini saptamak amacıyla yapılan çalışmanın sonucunda; kök sayısı, kök uzunluğu ve köklenme oranının oldukça değişkenlik gösterdiği, genellikle 4000 ppm IBA dozunun sağlıklı ve ekonomik bir çelik gelişimi ve üretimi için yeterli olduğu ve köklendirme amacıyla kullanılan perlit ortamında bitki çeliklerinin, diğer farklı köklenme ortamlarına (torf, kokopit, torf-perlit) göre daha iyi bir kök gelişimi sağladığı gözlenmiştir.

Çalışma sonucunda; köklendirme ortamları (torf, perlit, kokopit, torf-perlit) ve farklı dozlardaki IBA dozlarının yağ gülü, kadıntuzluğu, biberiye ve lavanta çeliklerinde köklenmeye genelde olumlu etkisinin olduğu saptanmıştır.

\section{Kaynaklar}

Alp, Ş., Yıldız, K., Türkoğlu, N., Çı̆̆, A., Aşur, F., 2010. Van ilindeki eski bahçe güllerinin değişik çelik tipleri ile çoğaltılması. Yüzüncü Yll Üniversitesi Tarım Bilimleri Dergisi, 20(3): 189-193.

Ayanoğlu, F., Mert, A., Kaya, A., 2000. Hatay florasında yetişen karabaş lavantanın (Lavandula stoechas subsp. stoechas L.) çelikle köklendirilmesi üzerine farklı lokasyonların ve hormon dozlarının etkisi. Turkish Journal of Agriculture and Forestry, 24(5): 607-610.

Baydar, H., 2009. Tıbbi ve Aromatik Bitkiler Bilimi ve Teknolojisi (Genişletilmiş 3. Baskı). Süleyman Demirel Üniversitesi Dergisi Yayınları, No: 51, Isparta.

Bayraktar, A., Atar, F., Yıldırım, N., Turna, İ., 2018. Effects of different media and hormones on propagation by cuttings of European yew (Taxus baccata L.). Šumarski List, 142(9-10): 509-516.

Dumitrascu, M., Stanica, F., Peticila, A.G., Davidescu V.E., Madjar, R.M., 2003. Rooting of evergreen stem cuttings in different substrates. Acta Horticulturae, 608(1): 267-271.

Ercişli, S., Anapalı, Ö., Eşitken, A., Şahin, Ü., 2002. The effects of IBA, rooting media and cutting collection time on rooting of kiwifruit. Gartenbauwissenchaft, 67(1): 34-38.

Gerçekcioğlu, R., 2009. Genel Meyvecilik. R. Gerçekcioğlu, Ş. Bilginer ve A. Soylu (Eds.), Çeliklerde Kök Olușumu, Nobel Yayınları, s. 247250.

Gudeva, L.K., Trajkova, F., Mihajlov, L., Troicki, J., 2017. Influence of different auxins on rooting of rosemary, sage and elderberry, Annual Research \& Review in Biology, 12(5): 1-8. 
Gümüşçü, A., Gümüşçü, G., 2015. Bazı sideritis (Dağçayı) türlerinde çeliklerin köklenmesine hormonların etkisi. Harran Tarm ve Gida Bilimleri Dergisi, 18(2): 49-55.

Güneş, M., Şen, M., 2001. Bazı kuşburnu tiplerinin (Rosa $s p p$.) odun çelikleriyle çoğaltılabilirlikleri üzerinde bir araştırma. Bahçe, 30(1-2): 17-24.

Hartmann, H.T., Kester, D.E., 1983. Plant Propagation Principles and Practices, 4th Edition Prentice, Hall International, Inc., Englowood Cliffs, New Jersey.

Kalyoncu, H.I., Ersoy, N., Alparslan, F., 2016. Ada çay1 (Salvia officinalis L.)'nın yeşil çelikle çoğaltılması üzerine farklı nem ve hormon doz uygulamalarının etkileri. Selçuk Tarım Bilimleri Dergisi, 3(2): 171176.

Kara, N., Baydar, H., Erbaş, S., 2011. Farklı çelik alma dönemleri ve IBA dozlarının bazı tıbbi bitkilerin köklenmesi üzerine etkileri. Batı Akdeniz Tarımsal Araştırma Enstitüsü Derim Dergisi, 28(2): 71-81.

Kumar, S., Sharma, D.R., 2002. In vitro propagation of kiwifruit. Journal of Horticultural Science and Biotechnology, 77(5): 503-508.

Özcan, M., 1993. The effects of IBA dosages and time of preparing cuttings on rooting of wood cuttings of Hayward and Matua kiwi variety. Horticulture, 22(1): 85-90.
Özcan, İ.İ., Arabac1, O., Öğretmen, N.G., 2013. Lavanta (Lavandula hybrida)'nın köklenmesi üzerine farklı hormon dozları ve köklendirme ortamlarının etkisi. $V$. Süs Bitkileri Kongresi, Bildiriler Kitabı, 06-09 Mayıs, Yalova, s. 529.

Saffari, M., Saffari, V.R., 2012. Effects of media and indole butyric acid (IBA) concentrations on hopbush (Dodoneae viscosa L.) cuttings in green house, Annual Forestry Research, 55(1): 61-68.

Sevik, H., Guney, K., Topacoglu, O., Unal, C., 2015. The influences of rooting media and hormone application on rooting percentage and some root characters in Schefflera arboricola. International Journal of Pharmaceutical Science Invention, 4(2): 25-29.

Tinmaz, A.B., Polat, Z., Kaya, Y., 2014. Bazı origanum türlerinde biyolojik ajan uygulamalarının köklenme ve gelişme parametreleri üzerine etkisi. 2. Tlbbi ve Aromatik Bitkiler Sempozyumu, Bildiriler Kitab1, 2325 Eylül, Yalova, s. 213-217.

Ünal, O., Gökceoğlu, M., Topcuoğlu, Ş.F., 2004. Antalya endemiği origanum türlerinin tohum çimlenmesi ve çelikle çoğaltılması üzerinde araştırmalar. Akdeniz Üniversitesi Ziraat Fakültesi Dergisi, 17(2): 135147. 